\title{
Relationship between Mindfullness and Cognitive Abilities in Blind Veteran Athletes
}

\section{ART ICLE INF O}

\section{Article Type}

Descriptive Study

\section{Authors}

Rahmani J.* $M S C$,

Ajilchi B. ${ }^{1} P h D$,

Zareian E. ${ }^{1} P h D$

How to cite this article
Rahmani J, Ajilchi B, Zareian E.
Relationship between indfulness
and Cognitive Abilities in Blind
Veteran Athletes Iranian Journal
of War \& Public Health. 2017;
9(2):105-110.

*Motor Behavior Department, Physical Education \& Sport Sciences Faculty,

Allameh Tabataba'i University, Tehran, Iran

${ }^{1}$ Motor Behavior Department, Physical Education \& Sport Sciences Faculty,

Allameh Tabataba'i University, Tehran, Iran

\section{Correspondence}

Address: Physical Education \& Sport Sciences Faculty, In Front of the Olympic Hotel, Hakim Highway West, Tehran, Iran. Postal Code: 1485743411

Phone: +98 (21) 44118632

Fax: +98 (21) 44118629 j.rahmani1000@gmail.com

\section{Article History}

Received: November 5, 2016

Accepted: February 25, 2017

ePublished: April 24, 2017

\section{A B S T R A C T}

Aims Cognitive abilities and mindfulness are factors hugely improving athletic activities. Blind persons, due to their lack of visual fast and accurate information, have to try to do cognitive executive tasks. The aim of the study was to investigate the correlation between mindfulness and cognitive abilities in the athlete blind veterans.

Instrument \& Methods In the correlative descriptive-survey study, 104 female and male athlete blind veterans from West Azarbayjan and Kordestan provinces were studied in 2015. The subjects were selected via available sampling method. Data was collected by the mindfulness scale, attention and consciousness scale, and the cognitive abilities questionnaire. Data was analyzed by SPSS 22 software using Pearson correlation coefficient and linear regression analysis.

Findings Except in two components including inhibiting control and selective attention and planning, mindfulness positively and significantly correlated with cognitive abilities in other components $(\mathrm{p}<0.05)$. In addition, 0.438 of cognitive abilities variance in the blind persons were predicted by mindfulness $(\mathrm{p}=0.001)$.

Conclusion In the athlete blind veterans, mindfulness significantly correlates with some components of cognitive abilities including memory, decision-making, sustainable attention, social cognition, and cognitive flexibility. Therefore, regular mindfulness exercises can strengthen cognitive abilities in the blind veterans.

Keywords Mindfulness; Consciousness; Cognitive Abilities

\section{I T A T I O N L I N KS}

[1] Cognitive abilities and psychological health after traumatic brain ... [2] TCold cognitions and consumers' reactions to sporting event ... [3] Comparing executive cognitive functions of the brain in blind and ... [4] The relationship between mindfulness and executive functions in blind ... [5] Mechanisms of ... [6] Why we don't need selfesteem: On fundamental need, contingent love, and ... [7] Meditation, mindfulness and cognitive... [8] Compare mindfulness blind and ... [9] The relationship between mental toughness and physical female in ... [10] The effects of fatigue on decision making and shooting skilo ... [11] The effect of exercise on cognitive performance in soccer specific ... [12] Expertise and perceptual-cognitive performance in soccer ... [13] Mindfulness: A proposed operational ... [14] Cognitive-emotional interactions -Attention regulation ... [15] Relational frame theory, acceptance and commitment therapy, and a functional ... [16] Effects of mindfulness on psychological health: A review ... [17] Improving decision making through ... [18] Decision making, mindfulness, and mood: How mindfulness techniques can reduce the impact of biases and heuristics through improved decision makingand positive... [19] The relationship between mindfulness and sustained attention, selective ... [20] The potential benefits of mindfulness training in early childhood: A developmental social cognitive neuroscience ... [21] Mindfulness in Iran and the United States: Cross- cultural structural complexity and ... [22] NInventory cognitive abilities: Design and assess the psychometric ... [23] One Year Follow-Up of Mindful Sport Performance Enhancement (MSPE) With Archers, Golfers, and .. [24] On the biopsychosocial model, mindfulness meditation and [25] Evaluation of the mindfulness-acceptance-commitment (mac) approach for [26] Zen principles and mindfulness practice in dialectical behavior [27] The cognitive flexibility inventory: Instrument development ... [28] Acceptance and commitment therapy and contextual behavioral science ... [29] The study of the prevalence of academic ... 


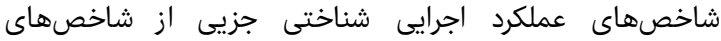

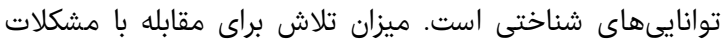

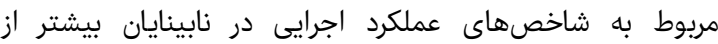

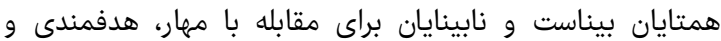

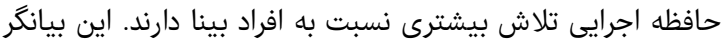

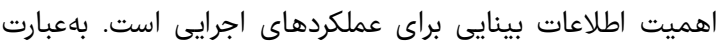

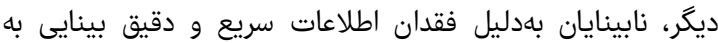

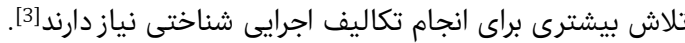

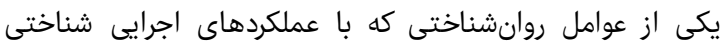

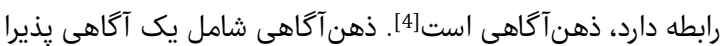

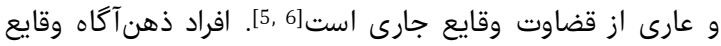

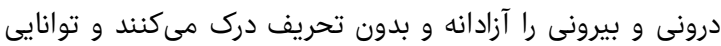

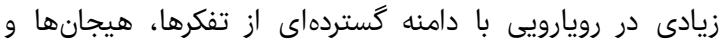

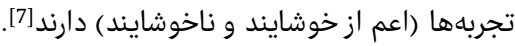

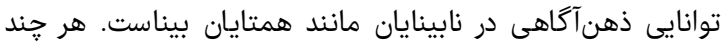

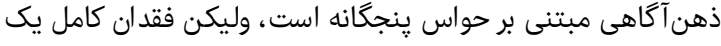

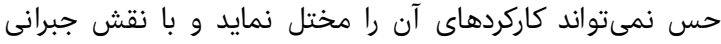

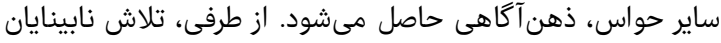

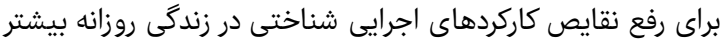

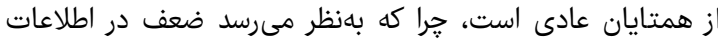

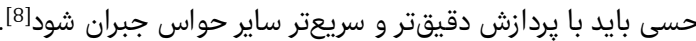

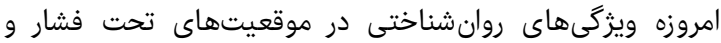

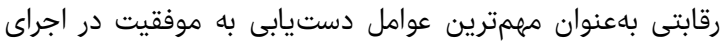

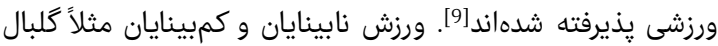

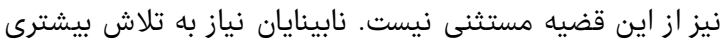

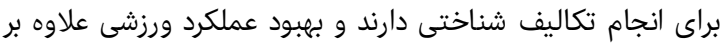

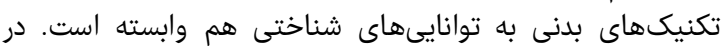

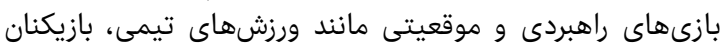

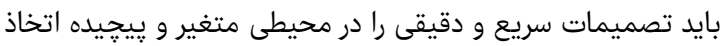

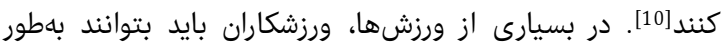

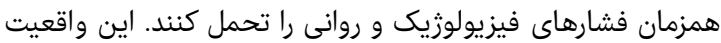

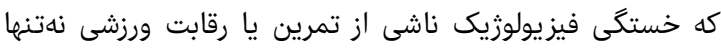

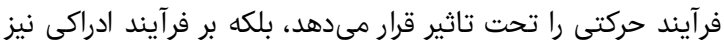

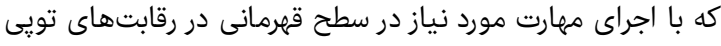

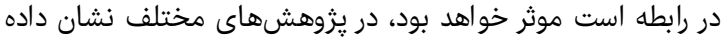

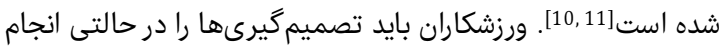

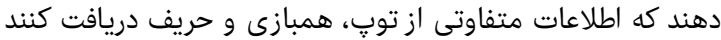

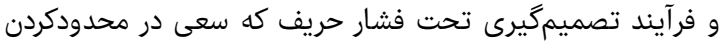

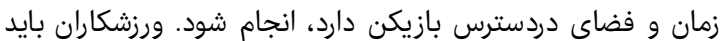

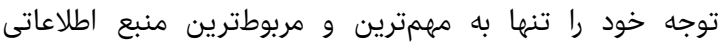

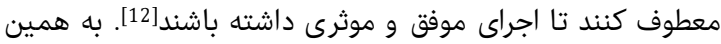

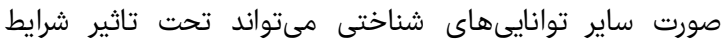

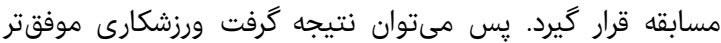

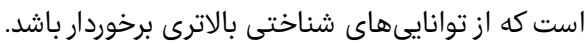

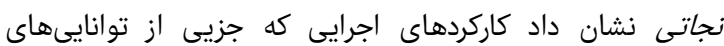

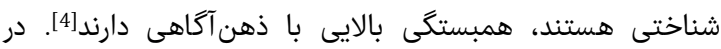

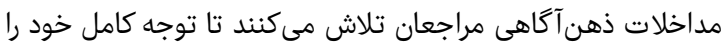

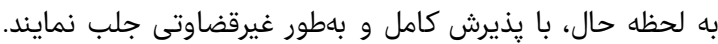

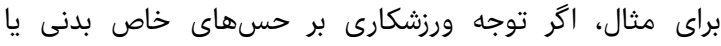

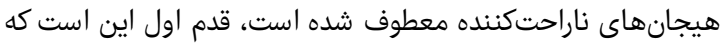

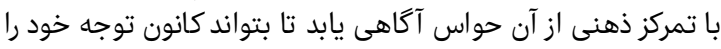

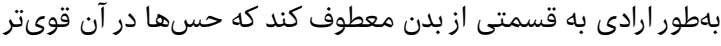

دوره 9، شماره r، بهار عqسا
رابطه ذهنآكاهى و توانايىهاى شناختى در

جانبازان نابيناى ورزشكار

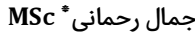

كروه رفتار حركتى، دانشكده تربيت بدانئ برانى و علوم ورزشى، دانشكاه علامه

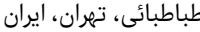

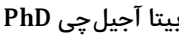

كروه رفتار حركتى، دانشكده تربيت بدنى و و علوم ورزشى، دانشكاه علامه

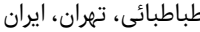

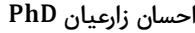

كروه رفتار حركتى، دانشكده تربيت بدان بدنى و علوم ورزشى، دانشكاه علامه

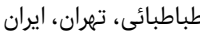

جكيده

هُهذاف: توانايىهاى شناختى و ذهن آكاهى عواملى هستند كه در اجراى عملكرد

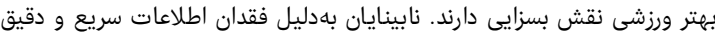

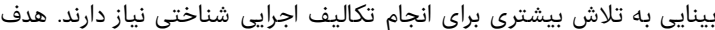

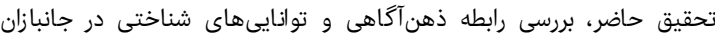
نابيناى ورزشكار بود.

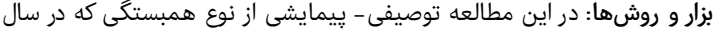

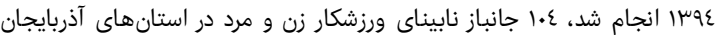

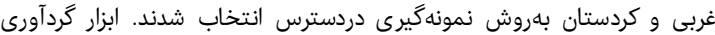

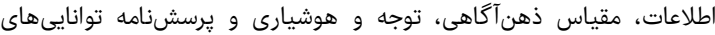

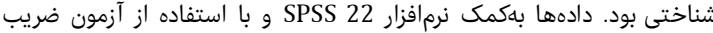

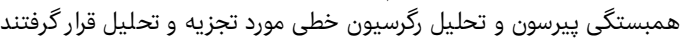

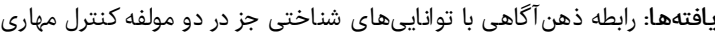

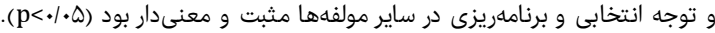

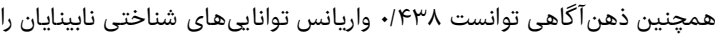

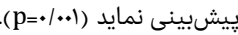

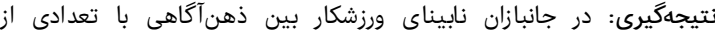

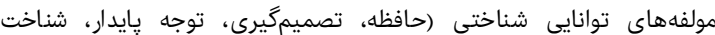

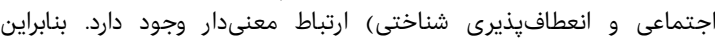

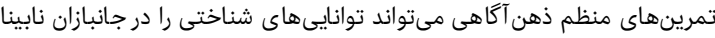

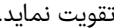
كليدوازمها: ذهن آكاهى، هوشيارى، توانايىهاى شناختى

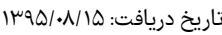

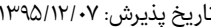

زتويسنده مسئول: j.rahmani1000@gmail.com

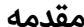

توانايىهاى شناختى شامل فرآيندهاى عصبى درگير در اكتساب،

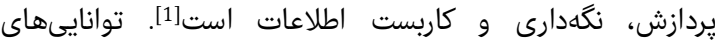

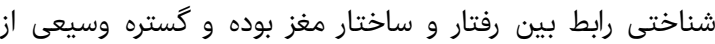

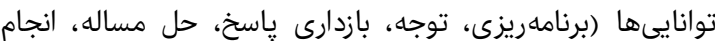

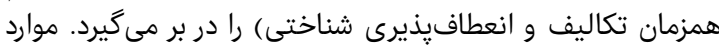

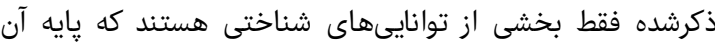

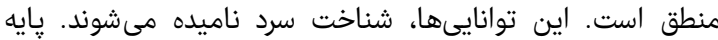

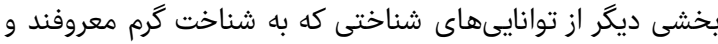

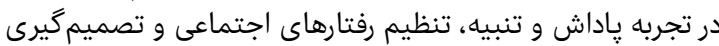

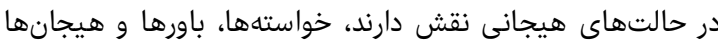

هستند]2].

شاخصهاى مربوط به توانايىهاى شناختى در يزوهش ما ثا شامل

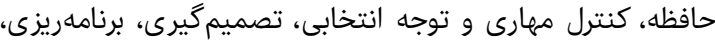

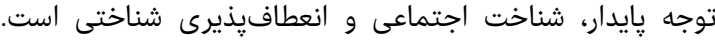

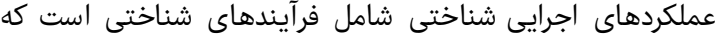

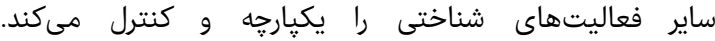

فصلنامه علمى - يُزوهشى طب جانباز 


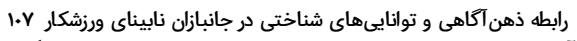

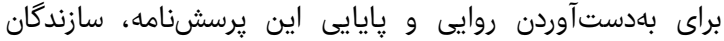

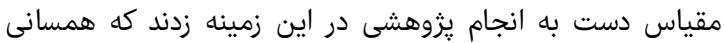

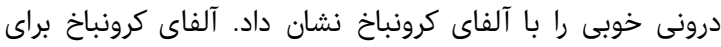

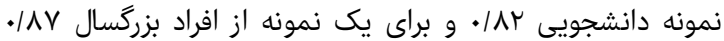

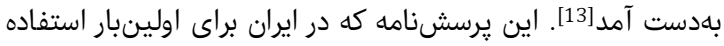

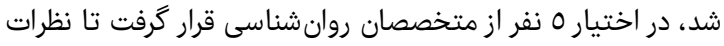

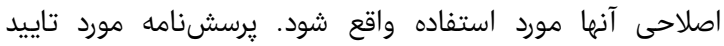

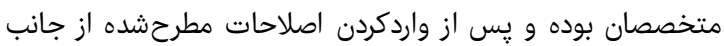

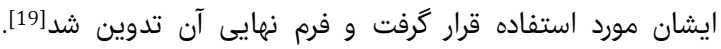

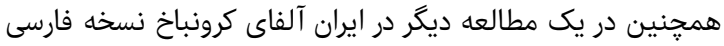

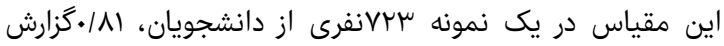

$$
\text { شده است[21]. }
$$

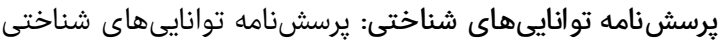

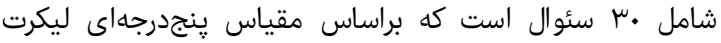

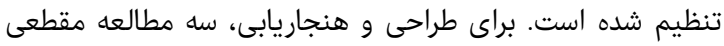

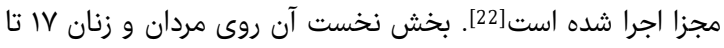

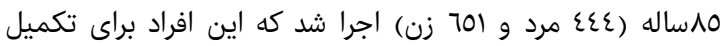

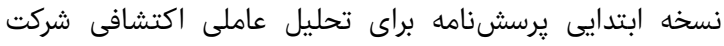

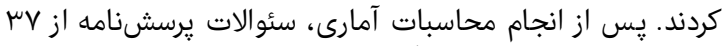

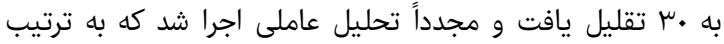

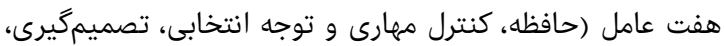

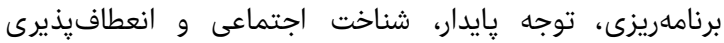

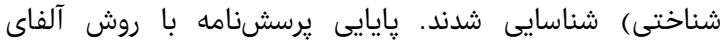

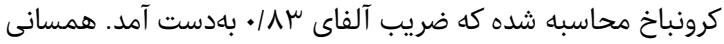

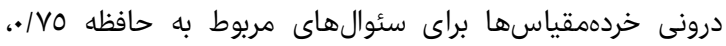

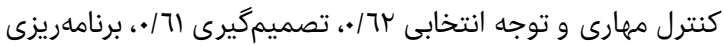
10V

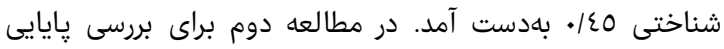

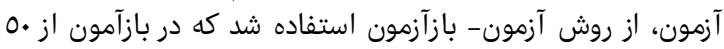

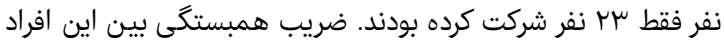

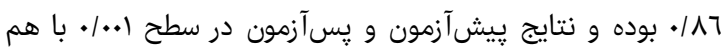

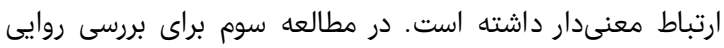

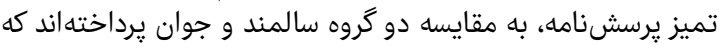

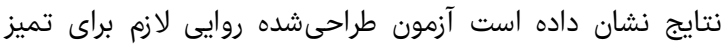

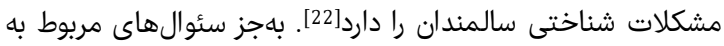

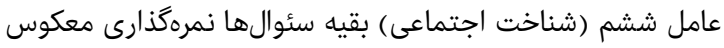
دارند.

تحليل دادهها با استفاده از نرمافزار SPSS 22 انجام شد. براي

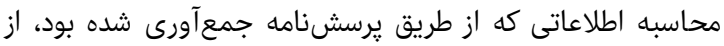

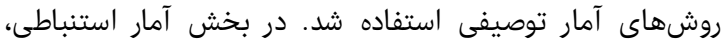

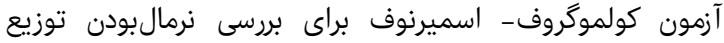

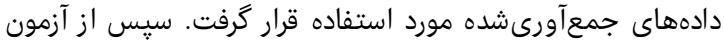

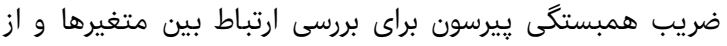

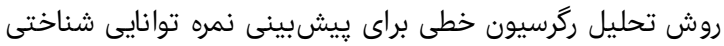

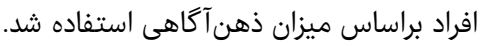

\section{يافتهها}

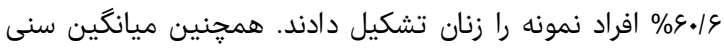
افراد نمونه

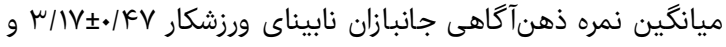

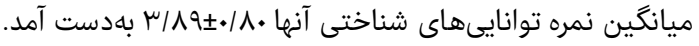

هستند. ورزشكار مىتواند از طريق تنفس، آكاهى خود را بهشيوهاى آى آنا

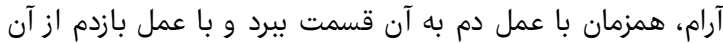

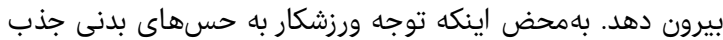

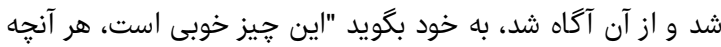

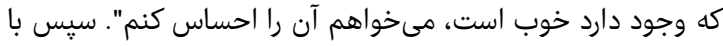

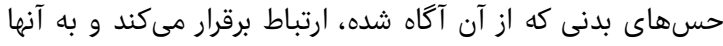

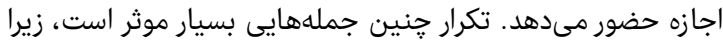

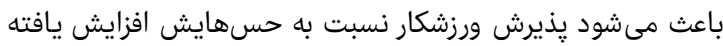

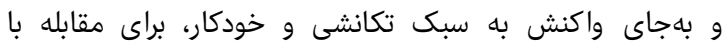
مشكلات شناختى، ماهرانه عمل كند [بند

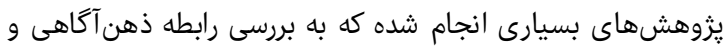

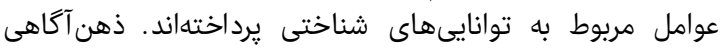

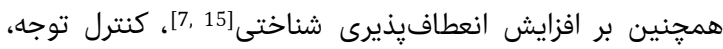

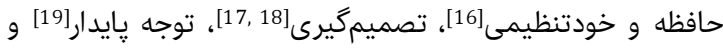

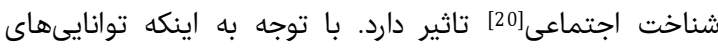

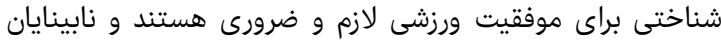

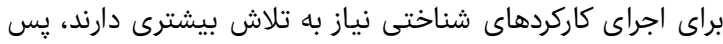

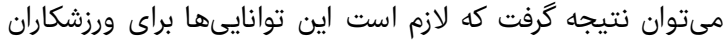

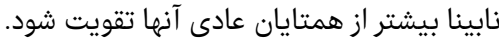

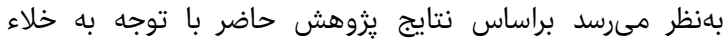

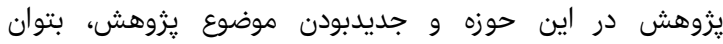

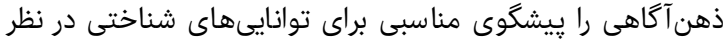

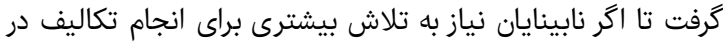

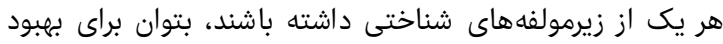

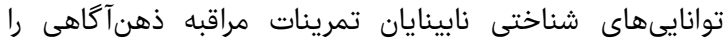
يُيشنهاد نمود.

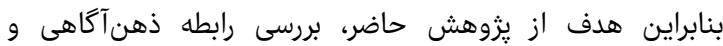

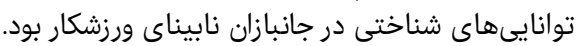

ابزار و روشها

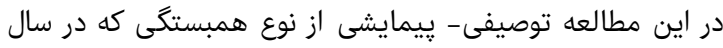

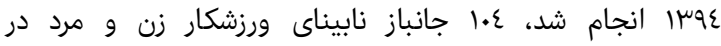

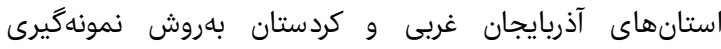
دردسترس بهعنوان نمونه تحقيق انتخاب شدرنداب

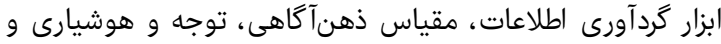
يرسشنامه توانايىهاى شناختى بود.

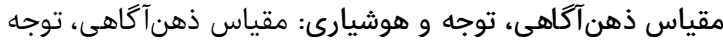

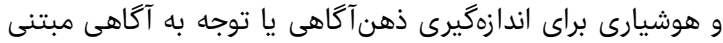

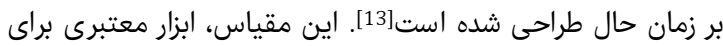

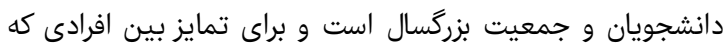

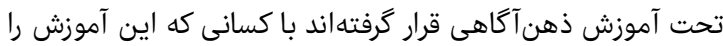

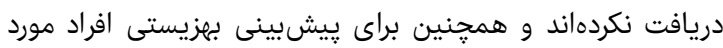

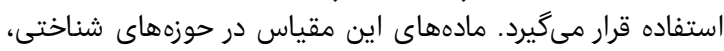

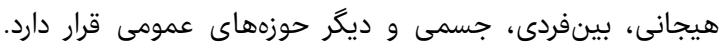

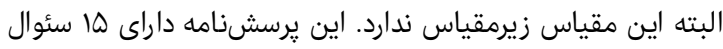

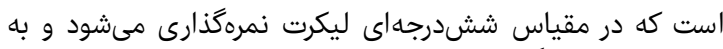

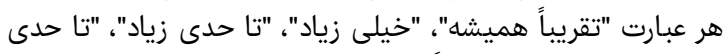

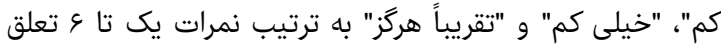

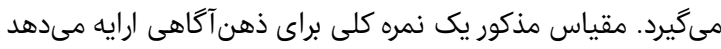

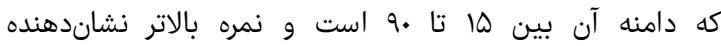

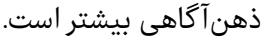


مىتوان توانايى خودتنظيمى توجه و هدايت آن به طرف تكليف

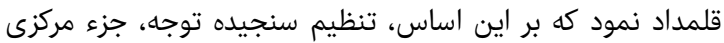

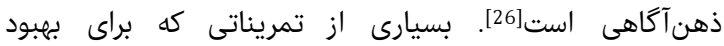

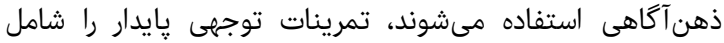

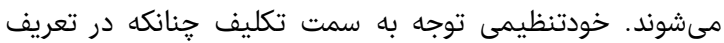

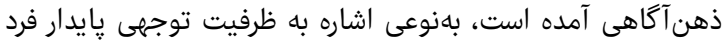

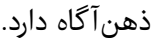

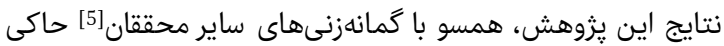

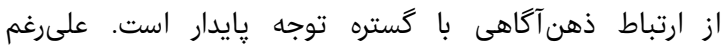

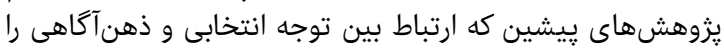

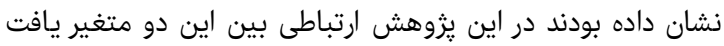

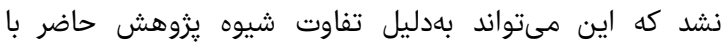

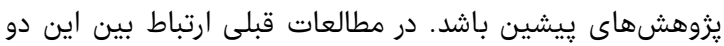

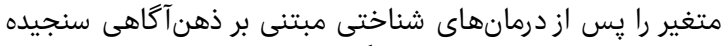

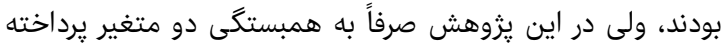
شده بود.

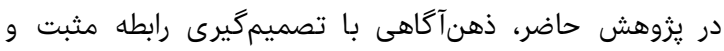

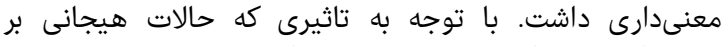

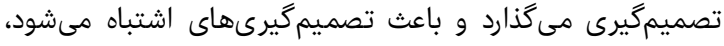

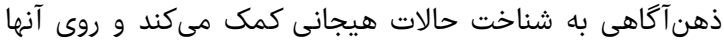

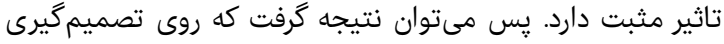

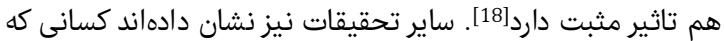

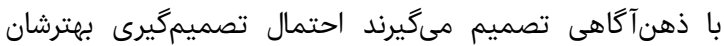

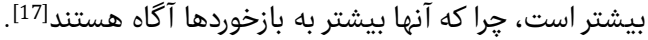

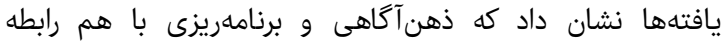

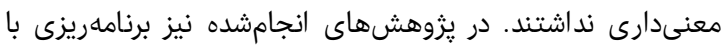

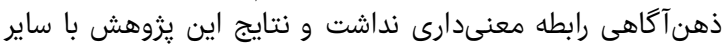

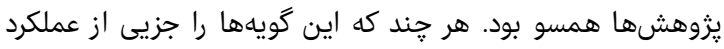

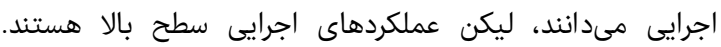

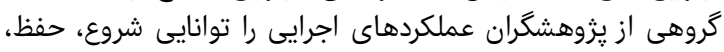

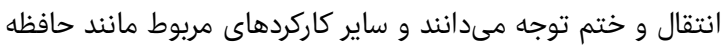

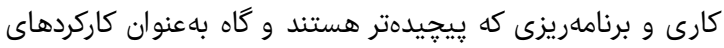

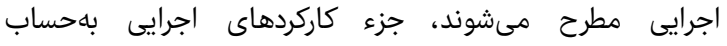

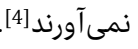
شناخت اجتماعى، مولفه ديكرى از توانايىهاى شناختى است كه إنه

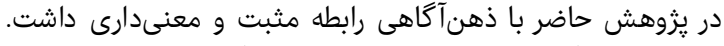

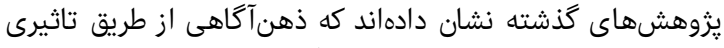

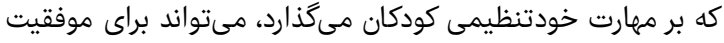

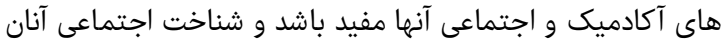

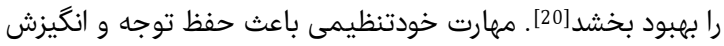

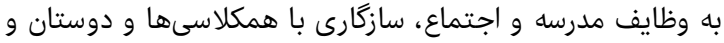

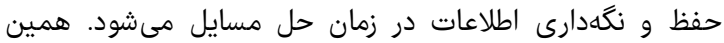

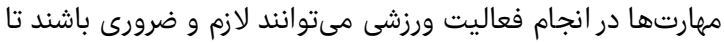

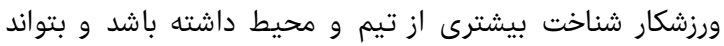

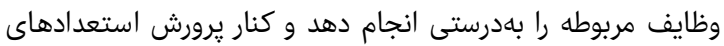

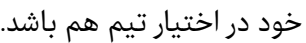

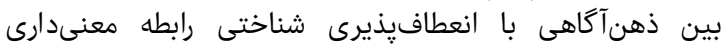

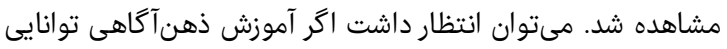

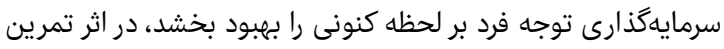

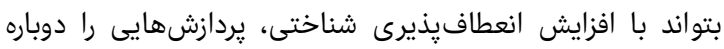

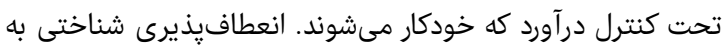

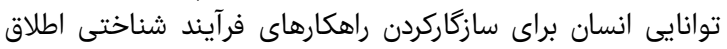

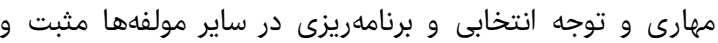
معنى ار و داراى همبستخى بالايى بود (جدول r r).

جدول () توزيع فراوانى مشخصات جمعيت شناختى جانبازان ورزشكار نابينا (1.K)

\begin{tabular}{|c|c|c|}
\hline درصد | در & تعداد & مشخصات جمعيت شناختى \\
\hline & & جنسيت \\
\hline$\mu q / k$ & $k_{1}$ & زن \\
\hline 9.16 & sk & مرد \\
\hline & & محدوده سنى \\
\hline$r r / I$ & r & ها تا هب سال \\
\hline$K \Delta / K$ & kV & هץ تا هץ سال \\
\hline$\mu r / V$ & $\mu k$ & ل \\
\hline
\end{tabular}

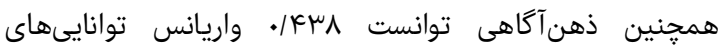

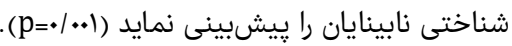

\begin{tabular}{|c|c|}
\hline ضريب همبستگى با ذهن آكاهى & توانايىهاى شناختى و مولفههاى آن \\
\hline$\cdot / \mathbb{k} \mu^{* *}$ & نمره كل توانايىهاى شناختى \\
\hline$\cdot \mid K^{* *}$ & حافظه ح \\
\hline $.1 .9 \mathrm{~V}$ & كنترل مهارى و توجه انتخابى \\
\hline$\cdot \mid \Delta K^{* *}$ & تصميمگيرى \\
\hline$\cdot / 14$ & برنامهريزى \\
\hline.$/ 4 k^{* *}$ & توجه يايدار \\
\hline.$/ T \mu^{*}$ & شناخت اجتماعى \\
\hline$\cdot|\mu|^{* *}$ & انعطافيذيرى شناختى \\
\hline
\end{tabular}

بحث

با توجه به نتايج يزوهش مشاهده شد كه ذهن آكاهى و مولفههاى

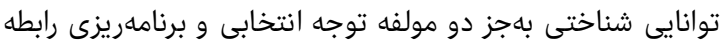

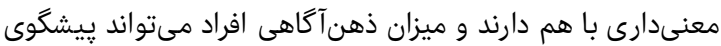

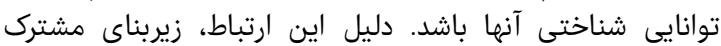

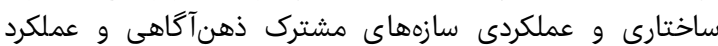

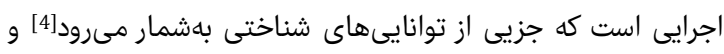

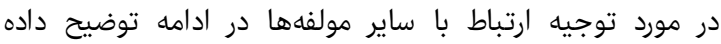

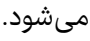

مداخلههاى مبتنى بر ذهن آكاهى با تاكيد بردي بر توجه آكاهانه به حال،

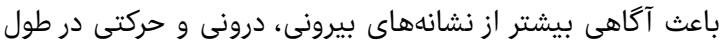

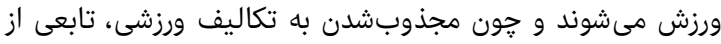

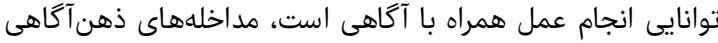

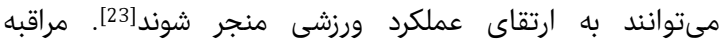

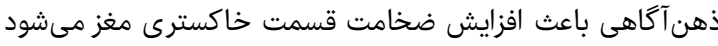

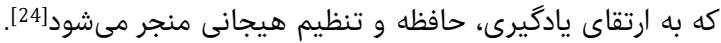

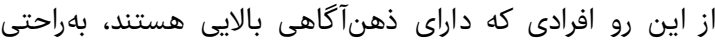

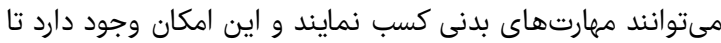

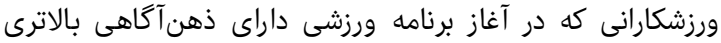

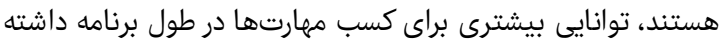

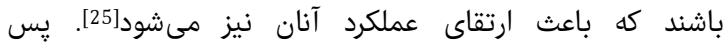

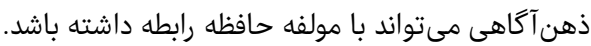

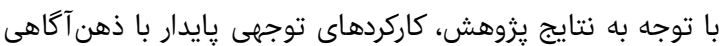

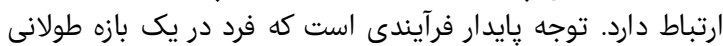

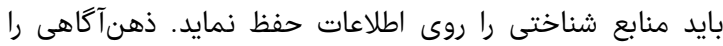




\section{نتيجه نايرى}

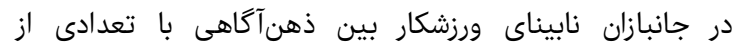

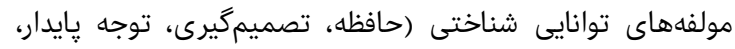

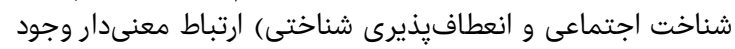

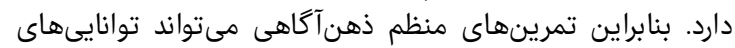
شناختى را در جانبازان نابينا تقويت نمايد.

تشكر و قدردانى: از تمام دوستان و عزيزانى كه ما را در اجراى اين إناين

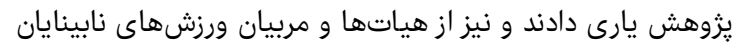

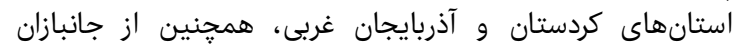

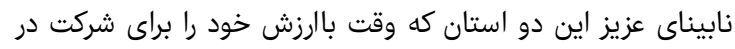

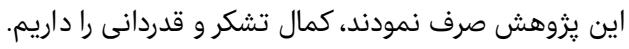

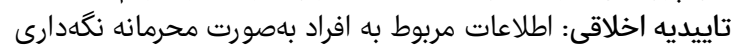

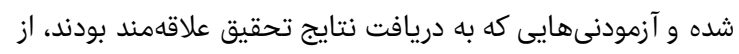

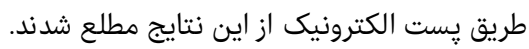

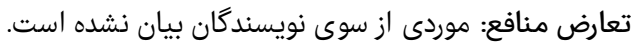

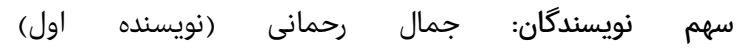

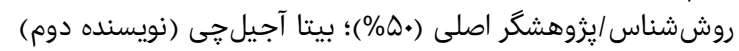

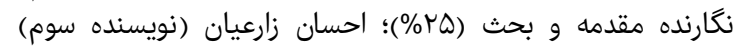

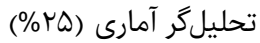

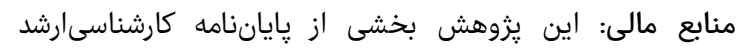
روانشناسى ورزشى دانشكده تربيت بدنى و و علوم ورزشى دانشانياه علامه طباطبايى است.

منابع

1- Nazari R, Khairkhah F, Dehshiri M, Jaberi A, Bijani A. Cognitive abilities and psychological health after traumatic brain injury (TBI). J Babol Univ Med Sci. 2010;12(3):58-63. [Persian]

2- Madrigal R. Cold cognitions and consumers' reactions to sporting event outcomes. J Consum Psychol. 2008;18(4):304-19.

3- Nejati V. Comparing executive cognitive functions of the brain in blind and sighted. J Mil Med. 2011;12(4):217-21. [Persian]

4- Nejati V. The relationship between mindfulness and executive functions in blind veterans. Iran J War Public Health. 2010;3(1) 44-8. [Persian]

5- Shapiro SL, Carlson LE, Astin JA, Freedman B. Mechanisms of mindfulness. J Clin Psychol. 2006;62(3):373-86.

6- Ryan RM, Brown KW. Why we don't need self-esteem: On fundamental need, contingent love, and mindfulness. Psychoinquiry Inq. 2003;14(1):27-82.

7- Moore A, Malinowski P. Meditation, mindfulness and cognitive flexibility. Conscious Cogn. 2009;18(1):176-86.

8- Nejati V. Compare mindfulness blind and sighted. Sci J Forensic Med. 2009;15(4):262-5. [Persian]

9- Hatami F, Hatami Shahmir E, Adibpour N, Tahmasebi F. The relationship between mental toughness and physical female in students. Sports Psychol Stud. 2012;1(2):53-64. [Persian]

10- Royal KA, Farrow D, Mujika I, Halson SL, Pyne D, Abernethy $B$. The effects of fatigue on decision making and shooting skill performance in water polo players. J Sports Sci. 2006;24(8):807-15.
مى شود كه بهمنظور مواجهه با شرايط جديد و غيرمنتظره در محيط

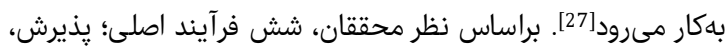

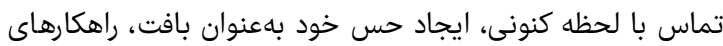

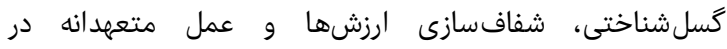

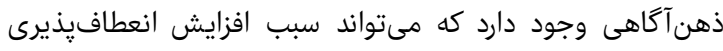
شناختى شود[28].

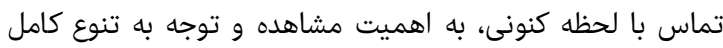

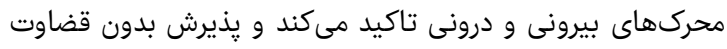

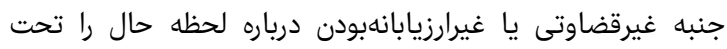

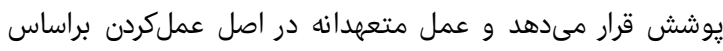

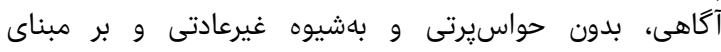

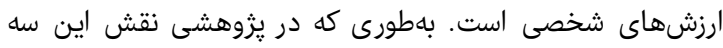

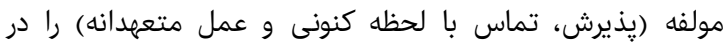

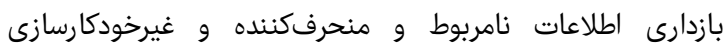

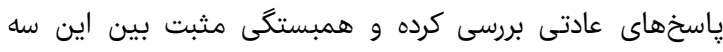

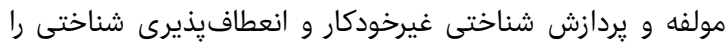

نشان دادهاند]7].

بنابراين بهنظر مىرسد كاهش يردازش إنهاى إنى شناختى خودكار و بهبود

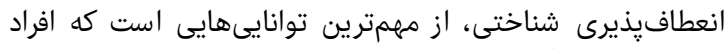

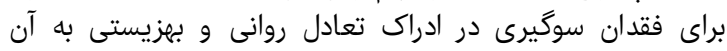

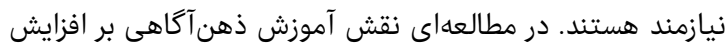

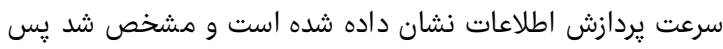

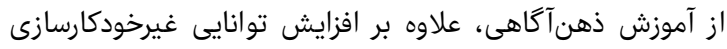

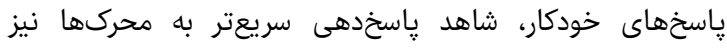

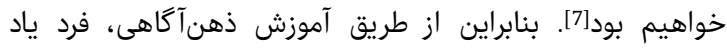

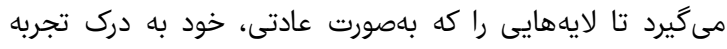

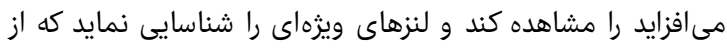

طريق آن به تماشاى دنيا مى مانشيند [29].

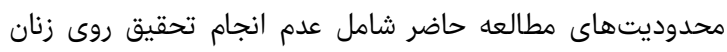

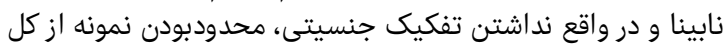

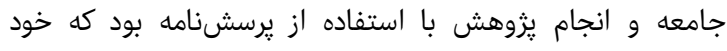

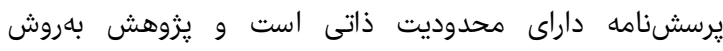

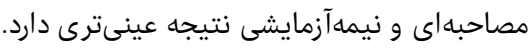

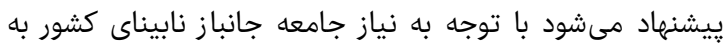

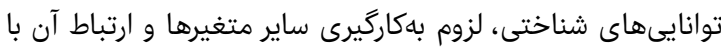

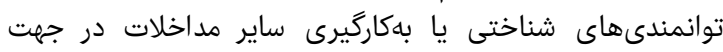

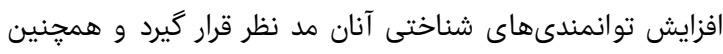

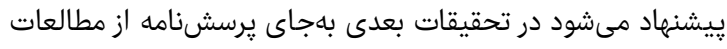
مداخلهاى استفاده شود. با توجه به شرايط ويزهاى كه نابينايان ورزشكار دارند و و مشكلات دوات

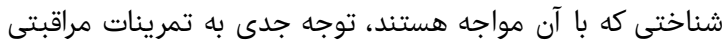

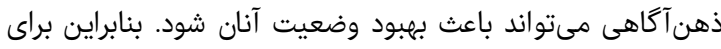

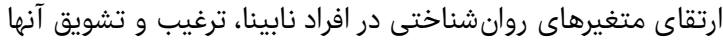

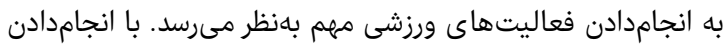

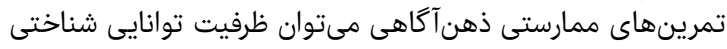

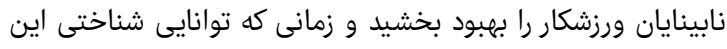

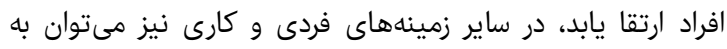

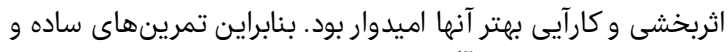

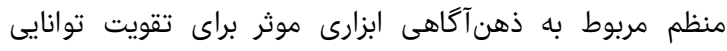
شناختى جانبازان نابينا است. 
perspective. Child Dev Perspect. 2012;6(2):154-60.

21- Ghorbani N, Watson PJ, Weathington BL. Mindfulness in Iran and the United States: Cross- cultural structural complexity and parallel relationships with psychological adjustment. Curr Psychol. 2009;28(4):211-24.

22- Nejati v. Inventory cognitive abilities: Design and assess the psychometric properties. Adv Cogn Sci. 2013;15(2):11-9. [Persian]

23- Thompson RW, Kaufman KA, de Petrillo LA, Glass CR, Arnkoff DB. One Year Follow-Up of Mindful Sport Performance Enhancement (MSPE) With Archers, Golfers, and Runners. J Clin Sport Psychol. 2011;5(2):99116.

24- Moran R. On the biopsychosocial model, mindfulness meditation and improving teaching and learning in osteopathy technique. Int $\mathrm{J}$ Osteopath Med. 2010;13(2):41-52.

25- Hasker SM. Evaluation of the mindfulnessacceptance-commitment (mac) approach for enhancing athletic performance [Dissertation]. India: Indiana University of Pennsylvania; 2010. p. 23.

26- Robins CJ. Zen principles and mindfulness practice in dialectical behavior therapy. Cogn Behav Pract. 2002;9(1):50-7.

27- Dennis JP, Vander Wal JS. The cognitive flexibility inventory: Instrument development and estimates of reliability and validity. Cogn Ther Res. 2010;34(3):24153.

28- Hayes S, Levin M, Plumb-Vilardaga J, Villatte J, Pistorello J. Acceptance and commitment therapy and contextual behavioral science: examining the progress of a distinctive model of behavioral and cognitive therapy. Behav Ther. 2013;44(2):180-98.

29- Sevary K. The study of the prevalence of academic procrastination in students (daughter's son) PNU Ahvaz. J Soc Cogn. 2013;2(1):62-8. [Persian]
11- McMorris T, Graydon J. The effect of exercise on cognitive performance in soccer specific tests. J Sports Sci. 1997;15(5):459-68.

12- Casanova F, Oliveira J, Williams M, Garganta J. Expertise and perceptual-cognitive performance in soccer: A review. Rev Port Cien Desp. 2009;9(1):115-22.

13- Bishop SR, Lau M, Shapiro S, Carlson L, Anderson ND, Carmody J. Mindfulness: A proposed operational definition. Clin Psychol Sci Pract. 2004;11(3):230-41.

14- Lutz A, Slagter HA, Dunne JD, Davidson RJ. Cognitiveemotional interactions -Attention regulation and monitoring in meditation. Trends Cogn Sci. 2008;12(4):163-9.

15- Fletcher L, Hayes SC. Relational frame theory, acceptance and commitment therapy, and a functional analytic definition of mindfulness. J Ration Cogn Ther. 2005;23(4):315-36.

16- Keng SL, Smoski MJ, Robins CJ. Effects of mindfulness on psychological health: A review of empirical studies. Clin Psycho Rev. 2011;31(6):1041-56.

17- Natalia K, Jochen R. Improving decision making through mindfulness. In: Reb J, Atkins P, editors. Forthcoming in mindfulness in organizations. Cambridge: Cambridge University Press; 2014. pp. 1-38.

18- Raglan GB, Schlkin J. Decision making, mindfulness, and mood: How mindfulness techniques can reduce the impact of biases and heuristics through improved decision making and positive affect. J Depress Anxiety. 2014;4:168-76.

19- Nejati V, Zabihzadeh A, Nikfarjam M. The relationship between mindfulness and sustained attention, selective functions. J Res Cogn Behav Sci. 2012;2(2):31-42. [Persian]

20- Zelazo PD, Kristen E. The potential benefits of mindfulness training in early childhood: A developmental social cognitive neuroscience 